\title{
Design, Development and Implementation of a Master of Science Degree in Modeling, Simulation, and Visualization
}

\section{Dr. Niaz Latif, Purdue University, Calumet}

Dr. Niaz Latif is the Dean of the School of Technology at Purdue University Calumet. He has also served for two years as the Dean of the Graduate School and additional two years as the Interim Associate Vice Chancellor for Research and Graduate Studies. Dr. Latif was responsible for the graduate education activities for 14 Master's Degree programs, development of new degree programs and courses. He earned his Ph.D. from the University of Missouri-Columbia and an M.S. from South Dakota State University (SDSU); both degrees are in Agricultural Engineering. He holds a B.Sc. in Mechanical Engineering from the University of Chittagong in Bangladesh. Dr. Latif has authored/co-authored numerous refereed journal articles and peer reviewed conference proceedings articles and has made national and international conference presentations. His publication record includes articles related to academic program development and assessment of academic programs. Dr. Latif was the Editor-in-Chief of the Journal of Engineering Technology.

\section{Prof. Joy L Colwell, Purdue University, Calumet (Tech)}

Joy L. Colwell is Director of Graduate Studies for Purdue University Calumet. She is a Professor of Organizational Leadership and Supervision, and former Assistant Dean of Graduate Studies in Technology. Professor Colwell writes frequently on the topics of soft skills in technology education, and on issues of graduate administration. 


\title{
Design, Development and Implementation of a Master of Science Degree in Modeling, Simulation, and Visualization
}

\begin{abstract}
The School of Technology at Purdue University Calumet designed, developed and implemented a Master of Science Degree in Modeling, Simulation, and Visualization (MSV). The degree is a 30 credit hour master's degree program, consisting of courses in problem solving with MSV tools and applications. In the development of this degree program, analyses were done of the stakeholder needs in the area; based on these analyses, the School designed the degree to meet "high-tech" workforce need in the region. The program is flexible enough to appeal to students having various academic or professional backgrounds within Science, Technology, Engineering and Mathematics (STEM) disciplines. The goal is to prepare graduates who would apply MSV skills in a variety of ways to solve industry and business problems. This paper describes the design, development and implementation of the interdisciplinary MSV graduate program in terms of, 1) needs and justification, 2) planning process, 3) program description and objectives, 4) curriculum, 5) implementation issues related to faculty, students, and resources, and 6) examples of MSV related industry projects. The description also includes the process, starting from a concept paper development through approval of the program by the State Commission of Higher Education.
\end{abstract}

\section{Introduction}

Advanced modeling, simulation, and visualization technologies provide an innovative way for humans to learn and understand extremely sophisticated concepts and problem solving skills as well as effectively design and optimize complex systems and processes. Through visualizing, manipulating, and interacting with computer-generated simulations and models, an individual can interact efficiently with 2D and 3D computerized environments in real time using his/her natural senses and skills. ${ }^{1}$ To meet the growing demand for the application of modeling, simulation and visualization in complex processes and systems, it is essential to educate and develop professionals who can incorporate advanced technologies to further the discipline and who can collaborate with professionals from other disciplines to solve industrial and societal problems. In this regard, the School of Technology at Purdue University Calumet (PUC) designed, developed and implemented a Master of Science Degree in Modeling, Simulation, and Visualization (MSV) to meet the "high-tech" workforce needs in this specialized area for the region. In the development of this degree program, analyses were done of the stakeholder needs in the area.

This paper describes the design, development and initial implementation of an interdisciplinary MSV graduate program. The paper includes the description of: 1) needs and justification, 2) planning process, 3) program description and objectives, 4) curriculum, 5) implementation issues related to faculty, students, and resources and 6) examples of MSV related industry projects. 


\section{Needs and Justification}

The justification and rationale for the MSV program is described in terms of institutional mission and goals, strength of campus facilities, regional benefit, workforce need, faculty expertise, employment outlook, and program availability in the field. The program is also justified in terms of national factors pertaining to this specialized area.

\section{Institutional Mission and Goals}

The mission of Purdue University Calumet is to offer a broad range of quality undergraduate, graduate, and continuing education programs that meet regional needs; to support excellence in teaching and learning; to advance and share knowledge through research and creative endeavor; and to work with the community to develop intellectual, cultural, economic, and human resources. ${ }^{2}$ The PUC strategic plan incorporates the University's mission to provide graduate study to meet the growing needs of profit and non-profit organizations in the Northwest Indiana region. ${ }^{3}$ Based upon the strategic plan, Purdue University Calumet is committed to contributing to the economic wellbeing of the region and to preparing students to be active and responsible members of a global society and workplace. This commitment increasingly means postbaccalaureate study that includes an understanding of complex areas of modern technology.

\section{Facilities}

Purdue University Calumet has already established a federally funded Center for Innovation in Visualization and Simulation (CIVS) with access to High Performance Computing (HPC) resources on campus through the Northwest Indiana Computing Grid (NWICG) that also connects resources at Purdue University (main campus) as well as the University of Notre Dame at South Bend, Indiana. This Center is capable of solving complex problems related to modeling, simulation and visualization. CIVS is a multidisciplinary center that combines advanced simulation techniques with $2 \mathrm{D}$ and $3 \mathrm{D}$ visualization and virtual reality technologies. ${ }^{4}$ Using the Center's resources, it is possible to see and interact with complex data in ways that are beneficial for experts, yet also understandable by audiences of many different backgrounds. The technology and resources at CIVS are currently being used to solve many different research questions, industrial, and community problems, as well as offering new possibilities for education and training. CIVS is continuing the development and implementation of cutting edge simulations, computer graphics, advanced visualization, and computing technology to serve faculty, staff, and students of PUC, as well as industry and the community. The Center is involved in instruction, research, and services in the area of biomedical, renewable energy, virtual engineering, and virtual learning. These facilities and resources position PUC to be a leader in the area of modeling, simulation, and visualization.

\section{Regional Benefit}

Furthermore, this initiative is fueling renewed economic development in Northwest Indiana, which requires a technologically and computationally sophisticated workforce. As noted above, there is no public or private university in Northwest Indiana that offers a graduate program in modeling, simulation, and visualization to help meet this need. Northwest Indiana's ties to the 
Chicago job market also make it a natural location for an advanced degree program in this field. Additionally, the program will serve as an invaluable driving force to advance experiential education and innovative research projects for PUC students. This is an emergent area of research and employment, so that few institutions have developed programs to meet this need. There are very few degree programs in modeling and simulation, and no institution offers a degree in modeling, simulation and visualization; at the time of the proposal, no institution of higher education in the State of Indiana offered a graduate degree in modeling simulation and visualization.

The availability of program graduates will benefit the business community of Northwest Indiana as well. Projections indicated that the demand for jobs in high-tech industries would continue to increase, and such businesses would have a growing need for employees with advanced degrees. Many technology companies are now moving into the Northwest Indiana-South Chicago area, including several at the new Purdue Technology Center in Merrillville, Indiana.

\section{Workforce Need}

It was anticipated that the graduates from the MSV program would meet the growing needs of profit and non-profit organizations in the Northwest Indiana region. The concept of developing a graduate degree program in modeling, simulation, and visualization was driven by requests that CIVS had received from area industrial partners, who wanted to pursue MSV-related projects and saw a need for training in this new area. Identifying careers in MSV presented a challenge at the time of concept. The careers in the Modeling, Simulation, and Visualization (MSV) area might not have a single specific Standard Occupational Classification (SOC) code in the Bureau of Labor Statistics and Occupational Outlook Handbook ${ }^{5}$, because MSV skills are skills which are used across a variety of disciplines. However, it can be helpful overall to consider such careers as equivalent to an advanced area in engineering and other professions requiring the skills and knowledge of MSV. Industrial Engineering Technology, Industrial Technology, and Industrial Engineering are a close category for the skills of an engineer with MSV training. Regional employers who have hired graduates with MSV skills include the oil refining industry, the power and light industry, steel-making and related industries, and biomedical industries.

It is generally acknowledged that Indiana needs more high-tech jobs, and this degree will prepare workers for new high skill, high wage jobs in high-tech fields. According to Rick Richards, writing in Indiana Business Magazine, only 1\% of Lake County's jobs were considered high tech in 2004. ${ }^{6}$ (The campus is located in Lake County). Additionally, the U.S. Bureau of Labor statistics indicated that the county lagged well behind the national high-tech average of 35 percent of all jobs. ${ }^{7}$ According to the Cyberstates ${ }^{8}$ report, Indiana's high tech employment data a few years later in 2008 reflected that Indiana was the 23rd ranked cyberstate, with 73,700 high tech workers, and the state ranked 45th in high-tech private sector workers (30 out of every 1,000 workers). On several indicators of high-tech employment, Indiana ranked no higher than 20th (payroll average wages for high tech workers, and number of high-tech establishments). And according to the 2000 census data, only 5.5\% of adults 25 or older in Lake County have attained a graduate or professional degree. ${ }^{9}$ 
For Economic Growth Region 1in Indiana, the percentage of the population over age 25 with a graduate or professional degree is 5.9\%. ${ }^{10}$ Economic Growth Region 1 includes Lake, Jasper, Newton, Porter, Pulaski, Starke and La Porte counties. (PUC is located in this Region.) This percentage for educational attainment, compared with a $7.2 \%$ rate for graduate and professional degrees in the state, and $8.9 \%$ for the nation, indicates that the region is below both state and national averages. ${ }^{11}$

\section{Faculty Expertise}

Purdue University Calumet has a number of faculty members who specialize in the areas of MSV at all levels. In addition, recently hired new faculty members are active in both research and teaching in modeling, simulation and visualization. Several faculty members from various STEM related academic departments have expertise in MSV and can teach graduate courses and advise graduate students in the program. See Table 1 below.

Table 1: PUC Faculty with MSV-related Experience (Proposal Phase)

Faculty (identified by title)

Professor of Mechanical Engineering, Dept. of Mechanical Engineering

Assistant Professor of Electrical \& Computer Engineering, Dept. of Electrical \& Computer Engineering Assistant Professor of Electrical \& Computer Engineering, Dept. of Electrical \& Computer Engineering

Head of Info Sys/ Professor of Management Info Sys, Dept. of Management

Professor of Electrical and Computer Engineering, Dept. of Electrical \& Computer Engineering

Associate Professor of Electrical and Computer Engineering, Dept. of Electrical \& Computer Engineering

Assistant Professor of Computer Graphics Technology, Dept. of Computer Info Tech \& Graphics

Associate Professor of Computer Information Technology, Dept. of Computer Info Tech \& Graphics

Assistant Professor of Physics \& Astronomy, Dept. of Chemistry \& Physics

Professor of Industrial Engineering Technology, Dept. of Engineering Technology

Associate Professor of Chemistry, Dept. of Chemistry \& Physics

Professor of Biology, Dept. of Biology

Associate Professor of Mathematics, Dept. of Math, Computer Science \& Stats

Assistant Professor of Applied Mathematics, Dept. of Math, Computer Science \& Stats

Assistant Professor of Electrical and Computer Engineering, Dept. of Electrical \& Computer Engineering

Continuing Lecturer of Mechanical Engineering, Dept. of Mechanical Engineering

Assistant Professor of Civil Engineering, Dept. of Mechanical Engineering

Assistant Professor of Mechanical Engineering, Dept. of Mechanical Engineering

Associate Professor of Computer Science, Dept. of Math, Computer Science \& Stats

Associate Professor of Computer Science, Dept. of Math, Computer Science \& Stats

Assistant Professor, Information Systems, Dept. of Information Systems

Professor and Director of CIVS

\section{Employment Outlook}

As noted above, the careers in the MSV area may not have a specific occupational code in the Bureau of Labor Statistics and Occupational Outlook Handbook since the skills are used in a 
variety of disciplines, but may be considered as an advanced area in engineering and other professions. Industrial Engineering is one of the closest categories for the skills of an engineer with training in the use of MSV tools. One may also consider the Engineering Management category, as those with a Master's degree would be considered at the same advanced level as Engineering Managers. The long-term projection, at the time the degree was planned and developed for Engineering Managers was for a 3.8\% increase for 2016. According to the longterm trends for Indiana, (Occupational Projections, Long Term), Industrial Engineers are expected to increase $18.2 \%$ by $2016 .{ }^{12}$ Overall engineering employment is expected to grow $11 \%$ over 2006-2016. ${ }^{13}$ Other professions which require the skills and knowledge of MSV would also fall into the professional or advanced level, and demand for those positions varies according to the professional discipline, but may include jobs in education, information technology, computer science, and related disciplines. According to the May 2008 National Industry-Specific Occupational Employment and Wage Estimates, (NAICS 541330) Engineering Services, the mean annual wage estimates for industrial engineers is $\$ 79,740 .^{14}$ Employment projections were based on the time period when the degree was moving from concept to final approval.

The degree itself, when approved, was ultimately assigned the Classification of Instructional Programs (CIP) code of 11.0804, Modeling, Virtual Environments and Simulation. This is associated with a cluster of Standard Occupational Classification System (SOC) codes, Computer and Information Research Scientists, Computer Programmers, Software Developers, Applications, and Multimedia Artists and Animators. When reviewing employment information, it is important to distinguish between positions that develop MSV tools and positions that use MSV tools. The information used to support the degree was more focused on those who use the tools in an engineering and technology context; the SOC codes associated with the eventual CIP code are also essential.

According to Indiana Career Connect, at the time degree approval was sought, more than 500 jobs listed were for some type of engineering, and five specific jobs listed modeling and simulation requirements, including research scientists, engineers, financial analysts, and health outcomes informaticist. ${ }^{15}$ More than forty-nine jobs were listed for engineers with modeling skills, and an additional eighteen jobs were listed for engineers with simulation skills. In the Economic Growth where the campus is located, thirty-four jobs in the Engineering area were listed.

\section{Sample Job Postings}

Internet searches show that jobs requiring modeling, simulation, and/or visualization skills appear in such diverse areas as Engineering, Information Technology, Military/Defense contractors, and Chemistry/Petroleum, as well as in the medical or medical devices field. According to an article reported in the New York Times, the job category with an expanding demand is for computer simulations in many fields, to understand complex phenomena. ${ }^{16}$ One professional in the field estimates that 400,000 people make a living in some aspect of simulation. The professional reported that the professional's company employs around 200 people with an average salary of $\$ 85,000$.

Sample job titles and employers advertising for modeling, simulation, and/or visualization skills appear in Table 2. 
Table 2: Sample Jobs Advertising for MSV Skills

\begin{tabular}{|l|l|l|}
\hline Job Title & Company, Location & Tasks requirement \\
\hline Software Engineer Lead & University in Louisiana & $\begin{array}{l}\text { Modeling and simulation and 3D } \\
\text { visualization }\end{array}$ \\
\hline Senior Engineer & Gold production & Modeling and Simulation \\
\hline Simulations \& Modeling Engineer & Non-profit in Massachusetts & Modeling and Simulations analysis \\
\hline $\begin{array}{l}\text { Modeling and Simulation Systems } \\
\text { Engineer }\end{array}$ & $\begin{array}{l}\text { Aerospace, electronics, etc. in } \\
\text { Illinois }\end{array}$ & Modeling and Simulation \\
\hline $\begin{array}{l}\text { Senior Modeling and Simulation } \\
\text { Software Engineer }\end{array}$ & Defense and Security & Modeling and Simulation \\
\hline $\begin{array}{l}\text { Lead Engineer } \\
\text { Modeling and Simulation Analyst }\end{array}$ & $\begin{array}{l}\text { Aireless Communication in } \\
\text { Arizona }\end{array}$ & Modeling and Simulation \\
\hline Modeling Simulation Engineer & Transportation in Wisconsin & $\begin{array}{l}\text { Rapid prototyping, modeling tools, and } \\
\text { graphics visualization. }\end{array}$ \\
\hline Principal Research Scientist & Pharmaceutical & Modeling and Simulation \\
\hline Health Outcomes Informaticist & Pharmaceutical & $\begin{array}{l}\text { Data-mining/visualization methods and } \\
\text { predictive modeling/simulation techniques. }\end{array}$ \\
\hline Magnetics Design Engineer & Automotive technologies & Modeling/Simulation \\
\hline Senior Product Engineer & Transmission & Heat, stress and vibration modeling \\
\hline Performance Engineer Specialist & Engine Manufacturing & Simulation/modeling of gas turbine cycles \\
\hline Design Engineer & Motion and Control Technol. & Simulation, modeling and statistical design \\
\hline
\end{tabular}

\section{National Factors}

Modeling and simulation (M \& S) are endorsed at the federal level as an area needed in the United States. It is endorsed through House Resolution Number 487, which passed in the House of Representatives by voice vote in $2007 .{ }^{17}$ The Resolution recognized the contribution of modeling and simulation technology to the security and prosperity of the United States, and recognized modeling and simulation as a National Critical Technology. In addition, the topic is of sufficient national importance to have a Congressional Caucus (Congressional Modeling and Simulation Caucus). The Caucus showcases M\&S initiatives, promotes the M\&S industry, and is a forum to understand the policy challenges facing this growing and versatile technology.

\section{Program Availability at National and Regional Levels}

Nationally there are few universities that offer graduate degrees in some combination of Modeling and Simulation, but almost none that combine modeling, simulation and visualization in one degree program. Some universities offer modeling and simulation (with or without visualization) as an area of specialization in either Engineering or Computer Science. Others have designed their programs with a focus towards a specific discipline/industry. The University of North Texas has established a Center for Advanced Scientific Computing and Modeling (CASCaM) for research, education, training and outreach in all facets of advanced scientific computing and modeling. However, no graduate degrees are offered through this center. The Department of Visualization at Texas A \& M offers a graduate degree in Visualization Sciences, to prepare students for careers in visualization. The program focuses on digital visualization pertaining to digital communication. The biomedical visualization program at University of Illinois in Chicago is focused on educating medical artists. A few additional schools offer graduate certificates in a 
related area. See Table 3 below for detailed information on some regional and national programs.

Table 3: MSV Programs Regionally and Nationally

\begin{tabular}{|c|c|c|}
\hline School & Program & Web information \\
\hline $\begin{array}{l}\text { University of Central } \\
\text { Florida }\end{array}$ & $\begin{array}{l}\text { Interdisciplinary Graduate } \\
\text { Programs in Modeling and Simulation }\end{array}$ & $\begin{array}{l}\text { http://www.ist.ucf.edu/phd/in } \\
\text { dex.html }\end{array}$ \\
\hline Old Dominion & $\begin{array}{l}\text { Grad program in Modeling and Simulation } \\
\text { MS and PhD }\end{array}$ & $\begin{array}{l}\text { http://eng.odu.edu/msgp/ } \\
\text { http://www.vmasc.odu.edu/ }\end{array}$ \\
\hline University of Florida & $\begin{array}{l}\text { Area of specialization in Engineering in } \\
\text { Modeling Simulation and Computer Graphics }\end{array}$ & $\begin{array}{l}\text { https://gradschool.ufl.edu/cata } \\
\text { log/current- } \\
\text { catalog/FOI/CEN01.htm }\end{array}$ \\
\hline University of Georgia & $\begin{array}{l}\text { The University of Georgia Distributed } \\
\text { Simulation Laboratory }\end{array}$ & $\begin{array}{l}\text { http://www.cs.uga.edu/ maria } \\
\text { /pads/index.htm }\end{array}$ \\
\hline Portland State & $\begin{array}{l}\text { Graduate Certificate in Computer Modeling \& } \\
\text { Simulation }\end{array}$ & $\begin{array}{l}\text { http://www.pdx.edu/sysc/prog } \\
\text { ram-systems-science- } \\
\text { graduate-certificates }\end{array}$ \\
\hline Georgia Tech & Modeling and Simulation Certificate & $\begin{array}{l}\text { http://www.defense.gatech.ed } \\
\text { u/certificates/modeling- } \\
\text { simulation/ }\end{array}$ \\
\hline $\begin{array}{l}\text { Arizona State } \\
\text { University }\end{array}$ & $\begin{array}{l}\text { Master of Engineering } \\
\text { Area of Study: Modeling \& Simulation }\end{array}$ & $\begin{array}{l}\text { http://cpd.asu.edu/online/?pag } \\
\mathrm{e}=\text { online meng ms }\end{array}$ \\
\hline Iowa State University & $\begin{array}{l}\text { Area of Specialization in Mechanical } \\
\text { Engineering in Simulation and Visualization }\end{array}$ & $\begin{array}{l}\text { http://www.eng.iastate.edu/gr } \\
\text { ad/me.asp }\end{array}$ \\
\hline
\end{tabular}

\section{Planning Process}

Purdue University requires a three-step process for approval of any new graduate degree program. These steps are: 1) a two-page concept paper, 2) a pre-proposal, and 3) the full proposal. A two page concept paper provides a brief rationale, relationship to similar programs within the system, sustainability, impact, and estimated resource need. Once the concept paper is approved a pre-proposal is submitted, and that requires all items from concept paper including expanded rationale, and market analysis to show anticipated demand. Once the pre-proposal is accepted, a full proposal is to be submitted following the Indiana Commission of Higher Education format with relevant information on budget and projected enrollment. The full proposal must be approved by the University's graduate council, provost's office and then submitted to the Commission for Higher Education for final approval

The planning for the proposed degree program in modeling, simulation, and visualization started in 2006 when Purdue University Calumet received a federal grant in support of the Northwest Indiana Computational Grid program mentioned above, designed to develop computational collaboration between PUC, Purdue University, and University of Notre Dame. A federal grant of \$1,550,000 was awarded to PUC for a high performance computing cluster in support of graduate education on visualization, simulation, and modeling. An additional \$4,750,000 federal grant was awarded to PUC to provide a state-of-the-art visualization lab and infrastructure in support of the modeling, simulation and visualization graduate degree program development.

The federal grant provided the budget for the program, as follows:

1) funding for the faculty time to develop the required graduate courses;

2) support of work related to overall program development;

3) providing external consulting service as needed; and 
4) enhancement of existing computational facilities (software and computational hardware).

While establishing a research center on visualization through innovation, PUC senior leadership team members decided to add the visualization program as a key component of the subsequently funded Washington Project. Meanwhile, the School of Technology and the School of Engineering, Mathematics, and Sciences initiated a process to design the modeling, simulation, and visualization graduate degree program using federal funding for the development of the MS degree, program related laboratories, establishment of the Center for Innovation in Visualization and Simulation (CIVS), and high performance computing capability.

Work on the graduate program began by identifying faculty members who already teach classes or conduct research in MSV-related areas, and were interested in participating in the proposed program. A nationally recognized facilitator with expertise in academic new program development was brought in to meet with the faculty. Under the facilitator's guidance, the faculty brainstormed anticipated goals and areas of focus for the new program. Given the mission of the university, the ultimate goal of training students for the workplace was quickly recognized. This led to a project-based approach that was more application-oriented, rather than a theoretical, doctoral-aimed approach. The brainstorming session also highlighted the need to create a focused core which would allow multiple disciplines to expand upon the core to tailor the educational program to the specific needs of the discipline.

The initial group of potential students was identified as coming from STEM disciplines, enabling the group to concentrate on courses in those areas. Core concepts were identified and grouped together for building the core courses. Concurrently, an external consultant (Carnegie Communications) was hired to identify similar programs nationally. While they found many programs that offer parts of the proposed program, or else focused on very specific applications of MSV, they did not find any directly comparable program to the one being proposed.

Using the results of the brainstorming session, a working group was established. This group represented a cross-section of faculty members from across the university who were interested in MSV. This group used the core concepts to identify currently offered courses that could be adopted or modified for the MSV program, as well as those that would need to be created for the program. This work was distributed among the group based on individual expertise. In the Fall of 2008, the working group submitted to the Graduate School a concept paper for a Master of Science degree in Modeling, Simulation, and Visualization, following the process outlined above. This concept paper was approved in Spring of 2009. Consequently, a pre-proposal was developed in the Fall of 2009. The working group recommended the concurrent development of seven core courses as the degree proposal was being developed and submitted. One of the core courses, the directed project capstone course, had already been approved as a graduate course for the campus. In the summer of 2009, three core courses were developed, and two of these courses were approved by the Graduate Council during the 2009-2010 academic year. The remaining three core courses were developed during summer 2010 and these courses were approved by the University's graduate council in 2010. As noted, the funding (for faculty time) for all course development came from federal grant. 


\section{Program Objectives, Curriculum, Courses, and the Semester plan}

The objectives of the program are to provide the following core competencies to the program graduates:

- Understand and effectively apply computing skills used in modeling, simulation, and visualization

- Apply required mathematical and statistical methods to the design of a model and simulation of a process

- Understand and apply modeling, simulation, and visualization processes and state of the art implementation tools to modeling, simulation, and visualization projects across disciplines, and

- Manage modeling, simulation, and visualization projects across disciplines

The degree program requires a total of thirty credit hours (ten 3-credit hour courses) to be completed, of which 18 credit hours are required core courses, with an additional 9 credit hours of electives. The additional 3 credit hours are the capstone directed project course in MSV, which is application-oriented and relevant to business and industry. The semester plan appears in Table 5.

The core courses are: 1) Unified Modeling Languages, 2) Simulation Techniques, 3). Visualization Techniques, 4) High Performance Computing, 5) Design and Analysis of Simulation Experiments, and 6) Software Project Management. Course descriptions for these courses are included in Table 4 below.

Table 4: Course Descriptions for MSV Core Courses

\begin{tabular}{|c|c|}
\hline $\begin{array}{l}\text { Unified Modeling } \\
\text { Language }\end{array}$ & $\begin{array}{l}\text { An introduction to Unified Modeling Language (UML) modeling and major UML diagrams } \\
\text { and how to apply them within object-oriented (OO) environments. Topics include UML } \\
\text { basics, OO system analysis and design, development process, and UML diagrams. }\end{array}$ \\
\hline $\begin{array}{l}\text { Simulation } \\
\text { Techniques }\end{array}$ & $\begin{array}{l}\text { An exploration of deterministic and stochastic simulation. Topics will include determining } \\
\text { range of validity, boundary issues, managing complexity, optimization and parallelization of } \\
\text { code, computational time management, adaptable meshes, fuzzy logic, and fidelity of } \\
\text { simulation. Random number generation will also be covered for stochastic simulations. } \\
\text { Examples and projects from a broad range of fields will be used. }\end{array}$ \\
\hline $\begin{array}{l}\text { Visualization } \\
\text { Techniques }\end{array}$ & $\begin{array}{l}\text { In this course graduate students in technology fields and related disciplines will learn how to } \\
\text { convey salient information about underlying data and processes for work involving data } \\
\text { visualization. Topics covered include various visualization techniques, issues in visual } \\
\text { analytics, perceptions and cognition, and application of visualization techniques to problems } \\
\text { in technical fields and related disciplines. }\end{array}$ \\
\hline $\begin{array}{l}\text { High Performance } \\
\text { Computing }\end{array}$ & $\begin{array}{l}\text { An introduction to High Performance Computing (HPC), with an emphasis on the } \\
\text { programming and analysis aspects of HPC for the practicing scientist, engineer or } \\
\text { technologist. This course will prepare students to analyze, design, implement and evaluate } \\
\text { parallel algorithms and computer codes. This course will cover the motivation for parallel } \\
\text { programming, a description and analysis of Amdahl's Law, and parallel-programming } \\
\text { methodology. Shared-memory and distributed-memory concepts will be compared, and } \\
\text { current application programming interfaces (APIs) will be covered. General knowledge of } \\
\text { undergraduate mathematics, science, engineering or technology required. }\end{array}$ \\
\hline
\end{tabular}




\begin{tabular}{|l|l|}
\hline $\begin{array}{l}\text { Design and } \\
\text { Analysis of } \\
\text { Simulation } \\
\text { Experiments }\end{array}$ & $\begin{array}{l}\text { A review of currently accepted practices in design of simulation experiments, with validation } \\
\text { and outcome analysis, and new techniques for model evaluation. Techniques covered may } \\
\text { include methods for uncertainty quantification in deterministic models, design of } \\
\text { experiments to match field experiments, data collection and sampling methods, data } \\
\text { reduction methods, and imaging and statistical visualization. }\end{array}$ \\
\hline $\begin{array}{l}\text { Software Project } \\
\text { Management }\end{array}$ & $\begin{array}{l}\text { The factors influencing decision during the initiation, implementation, and termination of } \\
\text { software projects are examined. Students work in project teams, using project management } \\
\text { tools to develop implementation strategies, characterize contemporary technology projects, } \\
\text { understand system perspective of projects, align projects with strategic objectives and learn } \\
\text { advanced tools and techniques used in projects. Examples and case studies from a wide range } \\
\text { of fields are utilized. }\end{array}$ \\
\hline
\end{tabular}

To be admitted into the program a student must meet the following prerequisites: a) 1 Semester Object Oriented Programming (sophomore level or above); b) 1 Semester Statistics/Probability (sophomore level or above); and c) 2 Semesters Calculus (Differential and Integral), or 1 Semester discrete mathematics or numerical methods (sophomore level or above).

Table 5: Semester plan for the MS in MSV degree program

Course Number(Credit Hours) Course Title

Semester 1

MGMT 55100 (3) Unified Modeling Language

TECH 56700 (3) Simulation Techniques

TECH 56500 (3) High Performance Computing

Semester 2

TECH 57700 (3)

TECH 57600 (3)

TECH 57500 (3 )

Visualization Techniques

Design and Analysis of Simulation Experiments

Software Project Management

Semester 3

Selective I (3)

Selective II(3)

Course in focus area (e.g. CS, ECE, IE, MATH, ME, TECH)

TECH 59800 (1)

Course in focus area (e.g. CS, ECE, IE, MATH, ME, TECH)

Phase I of Directed MS Project may be taken in this semester

Semester 4

TECH 59800 (2)

Selective III(3)

Directed MS Project (Phase II) or both phases (3 hrs)

Course in focus area (e.g. CS, ECE, IE, MATH, ME, TECH)

CS Computer Science

ECE Electrical and Computer Engineering

IE Industrial Engineering

MATH Mathematics

ME Mechanical Engineering

TECH Technology

\section{Implementation Issues Related to Faculty, Resources and Students}

Because of the lengthy process required to obtain approvals of the MSV degree, there was ample opportunity to consider the process for implementation. The planning for implementation was only preliminary during the approval process, and involved: 1) identifying the faculty members, 
2) developing the appropriate laboratory space, and 3) development of course content through grant-supported release time for some of the core courses in the plan of study. Some of the courses had not only been developed but had been offered to existing students, primarily in engineering and technology programs. Student interest in the offered courses was part of the analysis concerning the need for and interest in the MSV degree program.

Since all the additional actions needed for implementation were dependent upon approval, which was by no means certain, no further action was taken prior to approval. Because of the structure of the state approval process, active recruiting of students and scheduling of classes does not begin until after approval; for this particular proposal, the approval was not obtained until midsemester in the spring of 2012, when the fall schedule was already planned, so full efforts to implement were targeted for the following spring (2013), when there was still an opportunity to coordinate among programs to schedule appropriate classes with faculty involved in teaching courses for the degree.

Because this is an interdisciplinary degree, the implementation efforts for scheduling required coordination with multiple academic units within the University, a trickier and more timeconsuming process than coordinating within a department or school. Faculty members who will be teaching in the new degree program are supported by limited term lecturer funding to their respective schools, freeing up the faculty for the new degree courses. The institution committed to support for adjunct or limited term faculty as part of the degree development process. The School of Technology was given the responsibility for administering this interdisciplinary program.

It was hoped that the numbers of the first entering students would be sufficient to form a cohort group, to allow for efficient use of instructional resources. Of course, classes in a new degree may not fill in the first few semesters, so low enrollment courses should be contemplated. Approvals for running low enrollment courses in an interdisciplinary program could involve multiple academic units (and deans), and this was a factor to be considered in assigning faculty for the new degree program. One positive of a delayed start is that there is an opportunity to add to the inventory of projects available for students to work on in the capstone course, since there would be a 1-year lead in period after the initial course offerings before the capstone projects would be needed for the entering student cohort.

The resources needed for this program (lab space, hardware and software) were included in the grant funding mentioned above, in conjunction with the development of the CIVS Center. The CIVS Center operates independently of the MSV degree, so that the development of the degree will create a mutually beneficial relationship between the students in the program and the Center. Because this was part of an overall planned process, lab space for students working on directed projects within the MSV degree is available in the CIVS center labs. Local industries which supported the development of the degree would also be those interested in projects in the CIVS Center, and hiring graduates of the MSV program, or sending existing employees to the program for additional job skills.

As noted above, recruiting for the new degree program could not occur until after final state approval. Upon approval, the University began to publicize the new degree opportunity with 
press releases and information on the University website. An open house for the CIVS Center was combined with publicity on the MSV program, to demonstrate the types of projects and facilities available to the local community, potential students, and industry. Site visits to local industries which would have job needs for this type of skilled position were planned, along with email information and brochures on the new program. Students currently enrolled in undergraduate and graduate degrees were informed about the new option. Some recruiting efforts were directed at graduate students currently in engineering and technology master's programs. Since the MSV degree is ideal to enhance particular job skills in those areas, it was thought that there would be interest in an additional or dual master's degree for those students. A short video describing the degree program was also developed through the Graduate Studies office, for display through the campus' website and social media. It is anticipated that quite a few of the students who will enroll in the program will be working adults who wish to develop advanced skills for their professions, so employer visits will be very important in getting the word out to potential students. Recruitment is ongoing, with a planned cohort of students to start in Fall 13.

\section{Examples of MSV Related Industry Projects}

The CIVS Center has already completed dozens of MSV projects for local industry, along with additional projects undertaken for interdisciplinary collaborations on the campus. Research projects in the lab include projects in the areas of education and training, construction, economic development, engineering, energy, environment, healthcare, marketing, manufacturing science, service, and transportation. Examples include simulations and/or 3D models of various industrial components and equipment, such as cooling towers, blast and other types of furnaces, sinter coolers, water flow and fluid mechanics, and fly-through type visualizations of hospital and other types of facilities. ${ }^{18}$ Brain visualization, wind energy, traffic simulation and visualization, and virtual poetry show the range of projects students may be able to work on. Facilities rendered in 3D allow for assessment of potential equipment moves and changes to increase efficiency before a final change is made. Since 2009, the Center has helped local business and industry to save more than \$30 million in production and efficiency costs.

Table 6: Sample Industry-related MSV Projects

\begin{tabular}{|l|l|}
\hline Proposal Title & Sponsor Type \\
\hline Simulation of a SINTER COOLER & Steel Company \\
\hline Development of 3D Modeling for a Presentation & Surveying Company \\
\hline Evaluation of Cooling Tower Pumps & Refining company \\
\hline Pipe Support Analysis & \\
\hline Blast Furnace Design & Steel Company \\
\hline Hearth Simulation for Blast Furnace & Steel Company \\
\hline Circulating Water Inlet Pipe Study & Energy Company \\
\hline Flythrough Rendering of Facility & Healthcare \\
\hline Visualization of Airport Expansion & City \\
\hline
\end{tabular}

\section{Summary}

The process of developing a new degree in a developing area requires a great deal of planning, and does not happen without the efforts of a talented team of people. For institutions considering a high-tech degree program, allowing adequate planning time to 
research job demand and gain support of local industry is important. For public institutions, the time for obtaining approval of a new degree can be lengthy and this must be accounted for in the planning process. Further, managing the degree program once it has been developed requires interdisciplinary cooperation, which can make coordinating schedules and faculty assignments more complicated internally.

Note: Many faculty members are to be acknowledged in creating a degree proposal in a new area and bringing it to fruition. The authors would particularly like to acknowledge Dr. Bin Chen (Electrical and Computer Engineering), Dr. Charles Tseng (Molecular Biology \& Genomics), Dr. Chenn Qian Zhou (Mechanical Engineering), Dr. Daniel Suson (Physics), Dr. Ge Jin (Computer Graphics Technology), Dr. Lash Mapa (Mechanical Engineering Technology), Dr. Liberty Pelter (Chemistry), Dr. Lin Zhao (Information Systems), Dr. Lisa Hopp (Nursing), Dr. Shawn Slavin (Astrophysics), along with Dr. Ralph Rogers, Vice Chancellor of Academic Affairs, for their work in the degree proposal process. Additional campus members who were involved in the original concept should also be recognized: Dr. Robert Rivers (Education), and Dr. Rebecca Stankowski (Executive Director, MultiDisciplinary Studies \& Assessment), along with all others who contributed to the process.

\section{References}

\footnotetext{
${ }^{1}$ Author quote, http://www.innovativeworkforce.com/index.php?module=newsmodule\&src=@random41fbb196c9b04\&int=\&a ction=view\&id=743

${ }^{2}$ See http://webs.purduecal.edu/strategicplan/

${ }^{3}$ See Purdue University Calumet website http://webs.purduecal.edu/strategicplan/

${ }^{4}$ CIVS, http://webs.purduecal.edu/civs/

${ }^{5}$ http://www.bls.gov/ooh/ (Bureau of Labor Statistics Occupational Outlook Handbook)

${ }^{6}$ Richards, Rick A., Technology triad: developments to help Northwest Indiana catch up in creating high-tech jobs. (Regional report: Northwest focus) May 1, 2004.

${ }^{7}$ http://www.bls.gov/

${ }^{8}$ http://www.techamericafoundation.org/cyberstates2010-indiana (publication of AeA), available through High-Tech Jobs: AeA, Cyberstates 2008 (Washington DC: 2008).

${ }^{9}$ http://www.stats.indiana.edu/sip/ (select Educational Attainment, listed as Graduate or Professional Degree in table)

${ }^{10}$ (Select Economic Growth Regions, EGR1 for information pertaining to this area of the State.) http://www.stats.indiana.edu/dms4/new_dpage.asp?profile_id=302\&output_mode=1

${ }^{11}$ (Select Economic Growth Regions, EGR1 for information pertaining to this area of the State.) http://www.stats.indiana.edu/dms4/new_dpage.asp?profile_id=302\&output_mode=1

${ }^{12}$ Occupational Outlook Handbook $(\mathrm{OOH})$ statistics and projections (Bureau of Labor Statistics) are available through 2016 for degree areas. http://www.bls.gov/OCO; http://www.hoosierdata.in.gov/dpage.asp?id=39\&view_number=2\&menu_level=smenu1\&panel_number=2

13 (select Indiana, Architecture and Engineering for data on Employment and Growth); see also http://www.bls.gov/oco/pdf/ocos027.pdf

${ }^{14}$ http://www.bls.gov/oes/2008/may/naics5_541330.htm

15 www.indianacareerconnect.com

${ }^{16}$ New York Times on June 14, 2009, In Simulation Work, the Demand is Real by Conrad De Aennle
} 
${ }^{17}$ http://forbes.house.gov/Biography/mscaucus.htm Or see http://www.msco.mil/houseResolution.html

${ }^{18}$ http://webs.calumet.purdue.edu/civs/research/ 